\title{
STUDY OF PYHSICAL AND MOTORIC DEVELOPMENT AND EXPECTATION OF ATTENDANCE TO THE SPORTS ACTIVITIES
}

\author{
Dr. Şevki KOLUKISA (Correspondence Author)* Dr. Beytullah DÖNMEZ** Dr. \\ Kürşadhan DÖNMEZ ***
}

Giresun University- Education Faculty / Physical Education and Sports Department GiresunTurkey

E-mail: sevki.kolukisa@giresun.edu.tr*

Copyright (C) 2015 Dr. Şevki KOLUKISA (Correspondence Author)-Dr. Beytullah DÖNMEZ-Dr. Kürşadhan DÖNMEZ. This is an open access article distributed under the Eurasian Academy of Sciences License, which permits unrestricted use, distribution, and reproduction in any medium, provided the original work is properly cited.

\begin{abstract}
The ministry of educations main target is to bring up healthy individuals physically, morally, spiritually, socially and intellectually. Physical education lessons at school, for this reason takes part in educational programmes. This researchs purpose is to determine the expectation levels of secondary education students. Eight high schools with 468 students (216 girls and 252 boys ) from the educational system in the downtown of Giresun took part. To reach the determined aims in this research, a questionnaire of 35 questions and 3 parts with the leading points o f the data was developed. With the selected aims of physical education and sport, were selected from the national and foreignliterature which were also found in the first education schools and high schools of the ministry and education. The validity of the prepared survey and the suitability of the aims (because of testing ) were determined by taking the experts view. After required corrections were done, it was decided to increase more. The surveys were delivered to 8 high schools in the centre of Giresun that were established by the researcher. The datas that were taken by the survey were expressed and interpreted with frequencies and percentages. In comparisons $\chi^{2}$ (chi square) test was done. For statistical meaning 0.05 meaning level was chosen. According to the information that was taken by the research findings, high school students had some expectations according to the determined aims in the research, but these expectations
\end{abstract}

Keywords: Physical Education, Physical Development, High school, Sport, Expectation

\section{Öğrencilerinin Beden Eğitimi Dersinde Fiziksel ve Motorik Gelişim ile Sportif Faaliyetlere Katılım Beklentilerinin Araştırılması}

ÖZET: Milli Eğitimin temel amacı, kişiyi beden, zihin, ahlak, ruh ve sosyal bakımdan sağlıklı yetiştirmektir. Beden eğitimi dersi okullarda bu amaca hizmet etmek için eğitim programlarının bir parçası olarak yer almıştır. $\mathrm{Bu}$ araștırmanın amacı ortaöğretim öğrencilerinin beden eğitimi dersinden beklentileri ve beklentilerin gerçekleşme düzeyini belirlemektir. Giresun il merkezinde eğitim öğretim veren sekiz liseden toplam 468 öğrenci ( 216 kız, 252 erkek ) çalışmaya katılmıştır. Araştırmada belirlenen amaçlara ulaşabilmek için, elde edilen bilgiler 1şığında ve araştırmanın amacına uygun olarak üç bölümden ve toplam 35 sorudan oluşan anket formu geliştirilmiştir. Beden eğitimi ve sporla ilgili seçilen amaçlar, 
Milli Eğitim Bakanlığının İlköğretim Okulları Lise ve Dengi Okullar Beden Eğitimi Dersi İçin Öğretim Programında belirlediği amaçlar ile mevcut yerli ve yabancı literatürden seçilmiştir. Hazırlanan anket formunun geçerliliği ve amaçları test etme bakımından uygunluğu uzman görüşü alınarak belirlenmiştir. Gerekli düzeltmeler yapıldıktan sonra çoğaltılmasına karar verilmiştir. Anketler araştırmacı tarafından Giresun il merkezinde tespit edilen sekiz liseye dağıtılmıştır. Anketten elde edilen veriler frekans ve yüzdelerle açıklanmış ve yorumlanmıştır. Karşılaştırmalarda X2 ( Khi Kare ) testi uygulanmıştır. İstatistiksel anlamlılık için ise 0.05 anlamlılık düzeyi seçilmiştir. Araştırma bulgularından elde edilen bilgilere göre, lise öğrencilerinin araştırmada belirlenen amaçlara yönelik olarak beklentilerinin olduğu ancak beklentilerinin genellikle kısmen yada hiç gerçekleşmediği sonucuna varılmıştır.

\section{Anahtar Kelimeler: Beden Eğitimi, Fiziksel Gelişim, Lise, Spor,Beklenti}

\section{GíRIŞ}

Fizyolojik yaşam için oksijen, sıvı ve besin alımı, 1sı, basınç ve çoğalma önemli faktör ise , mental yaşam ruhsal ve psikolojik sağllk çok önemli ise, sosyal ve zihinsel yaşam için öğretim-eğitim önemli faktördür.(Dewey,1984)

Eğitim; bedensel, zihinsel ve ruhsal olarak bireyde istendik davranış değişikliği kazandırmak için yapılan planlı eylemdir.( Ertürk, 1979)

Eğitim, yüzyıllar boyu en çok konuşulan, tartışılan, eleştirilen, hakkında fikirler üretilen ve değişime uğrayıp, yenilenen konulardan birini teşkil etmiştir. İnsan yaşamının ayrılmaz bir parçası olan eğitim; denilebilir ki mevcut durumuyla hiç bir zaman yeterli görülmemiştir. Dolayısıyla insanın bireysel ve toplumsal kimliğinin oluşumunda, sosyo-elkonomik yaşamının şekillenmesinde birinci derecede önemli olan eğitim, tarih boyunca değişik etkilerle yapılanması ve insanlığın gelişme süreci ile olan yakın ilişkisi her zaman ilgililerce canlı tutulmuştur.(Varış,1994)

Fiziksel yapısı ve ruhsal yönüyle bir bütünlük gösteren insanın eğitiminde birçok bilim dalının katkısı bulunmaktadır. Ancak bu bilim dallarından çoğu, insanın zihinsel yeteneklerini geliştirmektedir. Örneğin; sosyal ve fen bilimleri bu gruba girmektedir. Güzel sanatların ise, bireyin görsel yetenek ve estetik duygularının geliştirilmesinde önemli katkıları vardır. Bunların dışında başka bir etkinlik türü daha vardır ki, insanın doku, organ ve işleyen tüm sistemleri ile doğrudan ilişkilidir. Bu etkinlikleri içeren disiplin ise beden eğitimidir.(Dönmez, 1995)

Eğitim, eğitilmesi gereken insanın gelecekteki davranışlarına yöneliktir ve bu davranışların nasıl, geliştirileceği eğitimin amaçlarında belirtilmiştir. Dolayısıyla eğitimin amacı; eğitilen insanın eğitim yoluyla gerçekleştirmesi gereken gellecekteki durumunu tanımlayan bir normdur. Beden eğitimi ve spora yönelik olarak eğitimin amacı ise eğitim ve öğretimde sportif faaliyetlerin niçin anlamlı ve önemli olduğu, bu yolla spor yapanın tutumu ve davranışlarında hangi değişikliklerin bekleneceği sorusuna cevap vermektir. Günümüzde beden eğitimi ve spor yetişmekte olan nesillerin temel kaynağı olan insamın, fiziksel, zihinsel, sosyal ve ruhsal gelişimini amaç edinen ve genel eğitimin tamamlayıcısı ve ayrılmaz bir parçası olarak görülen bilinçli ve planlı organizasyonlardır. Bu nedenlerden dolayı ortaöğretim programlarının öğretim programlarında beden eğitimi bir ders olarak yerini almıştır.( Tamer,1987) 
Bilindiği gibi ortaöğretim kuramları okul sistemimizin önemli bir dilimini oluşturan 15-17 yaş grubu öğrencilerin eğitim gördüğü öğrenim kurumlarıdır. İnsan olarak organik büyüme ve gelişme bu sürede çok hızlı olduğu gibi, çeşitli motor becerilerin elde edilmesi, zihinsel, duygusal ve motor öğrenmede de bu yaşlar öteki yaşlara göre en verimli dönemdir. Toplumsallaşma ve kültürleşme açısından da bu dönemin ayrı bir üstünlüğ ü vardır. Dolayısıyla ortaöğretim okullarında ders olarak okutulan beden eğitimi dersi birçok bakımdan önem taşımaktadır.( Öztürk,1982)

İnsanın iki ayrılmaz yönünü oluşturan fiziksel ve ruhsal yapısını olabildiği ölçüde geliştirme konusu başta devlet olmak üzere bir çok milli ve milletlerarası kuruluşların yakın ilgi ve görev alanına girmektedir. Okuma hakkı, serbest dolaşım hakkı, fiziksel ve ruhsal varlığı geliştirme hakk1, temel hak ve özgürlükler yasalarca güvence altına alınmıştır. Bu nedenle ülke insanlarının fiziksel yeteneklerinin geliştirilmesi bir eğitim konusu olarak devletlerin eğitim-öğretim politika ve programları içinde yer almıştır. Ülkemizde özellikle Cumhuriyet döneminden başlayarak yetiştirilecek gençlerin bedensel ve zihinsel eğitimleri konusundaki çalışmalar artarak sürdürülmüştür.( Unat,1964)

Başlangıçta her sınıftaki tüm öğrencilerin bedensel yeteneklerinin gelişimi öngörülerek hazırlanan okul beden eğitimi öğretim programları artık öğrencilerin ilgileri doğrultusunda ve başarılı oldukları spor dallarında etkinlik göstermelerine yönelik olarak hazırlanmaktadır. (Masser,1990)

Okul çağındaki çocuklarda her yönüyle sağlıklı bir gelişmenin olabilmesi, onların iyi hazırlanmış nitelikli bir genel eğitim görmelerine bağlıdır. Eğitim .bütün organizmayı ilgilendiren tamamıyla bir bedensel-zihinsel ilişkidir. Dolayısıyla eğitim programlarında beden ve zihin bir bütün olarak ele alınıp, değerlendirilmelidir. Çocukların yetişkinliğe geçiş dönemi olan ortaöğretim çağı, onların bedensel, ruhsal ve kültürel gelişiminin en üst düzeye ulaştı̆̆ bir dönemdir. (Gökmen,1983)

$\mathrm{Bu}$ dönemde öğrencilerin her türlü ihtiyaçlarına cevap verecek bir eğitime ihtiyaç vardır. $\mathrm{Bu}$ ihtiyaçlar ise, zihinsel ve ruhsal eğitimin yanında fiziksel eğitimin etkin ve verimli bir şekilde uygulanmasıyla giderilebilir. Eğitimciler, beden eğitimini sadece bir hareket eğitimi olarak ele almamaktadırlar. Hareketler yoluyla bireylerin bir bütün içinde eğitimini amaçlayan bilim dalı veya faaliyetler alanı olarak görmektedirler ( Tamer,1987)

Beden eğitimi ve sporu, boş zamanlarda oynanan oyunlar, okul içinde yapılan spor etkinlikleri ya da okul takımlarının okul dışında yaptığı spor karşılaşmaları olarak görmenin doğru bir yaklaşım olmadığını söylemek mümkündür. Buradan hareketle çağdaş bir eğitim sistemi içinde beden eğitimi ve spor eğitimi görmüş bireylerin şu özellikllere sahip olması beklenmektedir.(Dönmez,1995)

1- Bireyin, kendi fiziki kapasite ve sınırlılıkları hakkında bilgi sahibi olması,

2-Bireyin, çevresindeki imkanları verimli bir şekilde değerlendirebileceği geniş ve çeşitli faaliyetler ile sportif etkinlikler hakkında bilgi ve becerilere sahip olmas1,

3 -Bu faaliyetlerin ve sportif etkinliklerin bireye sağladığ fiziksel, duygusal ve sosyal faydaları hakkında bilimsel bilgilere sahip olması,

4-Kendi kendisinin ve başkalarının haklarını anlaması ve saygılı olması. 
Genel eğitimin tamamlayıcısı ve ayrılmaz bir parçası olan beden eğitimi vie spor aynı zamanda kişiliğin eğitimi durumundadır. Başka bir ifadeyle öğrencilerin gelişen özellikleri göz önünde tutularak onların fert ve toplum yönünden sağlıklı, mutlu, iyi ahlaklı ve dengeli bir kişilik sahibi, yaratıcı ve üretken; milli kültür değerlerini ve demokratik hayatın getirdiği davranışları kazanmış fertler olarak yetiştirilmelerinde bir eğitim unsuru olarak beden eğitimi ve spor önemli bir faaliyettir.

Günümüzde eğitim kurumları istenilen davranış değişikliklerini bireylere kazandıran yerlerdir. Dolayısıyla ortaöğretim programlarında yer alan beden eğitimi derslerindeki uygulamalarda öğrencilerin beklenti ve ihtiyaçları iyi tespit edilerek öğrencilerin ileriye yönelik beceriler kazanmaları sağlanabilir.

Türk milli Eğitiminin temel amaçları içinde ; Beden ,zihin,ahlak,ruh ve duygu bakımından dengeli ve sağlıklı şekilde gelişmiş bir kişiliğe ve karaktere,hür ve bilimsel düşünme gücüne,geniş bir dünya görüşüne sahip, insan haklarına saygılı,kişilik ve teşebbüse değer veren,topluma karşı sorumluluk duyan,yapıcı,yaratıcı ve verimli kişiler yetiştirmektir. (MEB, 1988)

Orta öğretimin lise dönemi 14-18 yaş grubunu kapsayan, öğrencilere meslek kazandırmayı ve onları yüksek öğretim kurumlarına hazırlamayı amaçlayan eğitim devresidir. (MEB, 1973 )

Beden eğitiminin amacını dört temel bölümde toparlamak mümkündür ;
a-Organik gelişim
b-Psiko-motor (kas-sinir) gelişim
c-Zihinsel gelişim ve
d- Ruhsal gelişim (Will, and Carl.1979)
Lumpkin ise beden eğitimini üç grupta toplamıştır ;

a-Bilişsel alan : Vücut fonksiyonlarını kavrama,sağlık,büyüme,gelişme sürecini kavrama, motor öğrenme, oyun ve emniyet kural ve becerilerini kavrama,stratejiler geliştirme ve değerlendirme,

b- Duyuşsal alan; Kendine güvenme, değer anlayışı,karakter geliştirme,iletişim becerileri,meraklılığı geliştirme ve sportmenlik becerileri,

c-Psiko-motor alan : Vücudu ısındırma ve alıştırma ve alıştırma becerileri,temel hareket becerileri,motor becerileri,bedeni mekanik ve yeterlilik ( kardiyovasküler dayanıklılık,kas gücü ve dayanıklılığı, elastikiyet ve ceviklik kazanma.( Lumpkin,1986)

$\mathrm{Bu}$ araştırma ile ortaöğretim okullarının öğretim programında yer alan beden eğitimi dersine yönelik amaçlardan yola çıkarak öğrencilerin beden eğitimi dersinden orta öğretim ögrencilerinin beden eğitimi dersinde fiziksel ve motorik gelişim beklentilerinin ve bu beklentilerinin gerçekleşme düzeylerini belirlemek amaçlanmaktadır.

$\mathrm{Bu}$ temel amaca ulaşabilmek için ; Kız ve erkek öğrencilerin beden eğitimi dersinde ki fiziksel ve motorik gelişim beklentileri ve bu beklentilerinin ne derece gerçekleştiği ve iki grup arasındaki farklılık var mıdır? sorusu araştırılmıştır. 


\section{MATERYAL ve METOD}

$\mathrm{Bu}$ araştırma, Giresun ilinde lise son sınıflarda okuyan ve beden eğitimi dersini alan ve tesadüfi yöntemle seçilen $216 \mathrm{kız}, 252$ erkek toplam 468 öğrenci ile anket uygulayarak yapılmıştır.

Deneklere 15 kişisel, 20 alan sorusu olmak üzere; beden eğitimi dersinden beklentileri ve beklentilerinin gerçekleştirme düzeyi ile ilgili sorular yöneltilmiştir. Giresun ilinde eğitim veren H. Bozbağ Anadolu Lisesi (69), Atatürk Anadolu Lisesi (63), Aksu Anadolu Lisesi (55) G. İmam-Hatip Lisesi (35), Giresun Anadolu Lisesi (80), İMKB Öğretmen Lisesi (75), A.End.Teknik Lisesi (34) ve A.Ticaret Lisesi (57) öğrenci katılmıştır.

Veriler SPSS programı kullanılarak Beden Eğitimi dersinden öğrencilerin fiziksel ve motorik gelişim beklentileri ve beklentilerinin gerçekleşme düzeyini saptamak üzere frekans (f),yüzde (\%) hesaplaması yapılarak cinsiyet değişkenine göre farklılık olup olmadığını bulmak için ( $\mathrm{X}^{2}$ ) testi yapılmış $\mathrm{P}<0.05$ 'e göre sonuçlar yorumlanmıştır

\section{BULGULAR}

TABLO -1 Cinsiyet değişkenine göre beden eğitimi dersindeki çalışmalarla fiziksel gelişim sağlama konusundaki öğrenci beklentileri

\begin{tabular}{|c|c|c|c|c|c|c|c|c|c|c|c|c|}
\hline \multirow[t]{3}{*}{ Cinsiyet } & \multicolumn{4}{|c|}{ Beklenti } & & \multicolumn{6}{|c|}{ Beklentinin Gerçekleşme Düzeyi } & \multirow[t]{3}{*}{ Toplam } \\
\hline & \multicolumn{2}{|c|}{ Var } & \multicolumn{2}{|c|}{ Yok } & & \multicolumn{2}{|c|}{ Tamamen } & \multicolumn{2}{|c|}{ Kismen } & \multicolumn{2}{|c|}{ Hiç } & \\
\hline & $\mathrm{f}$ & $\%$ & $\mathrm{f}$ & $\%$ & Toplam & $\mathrm{f}$ & $\%$ & f & $\%$ & $f$ & $\%$ & \\
\hline $\mathrm{K} 1 \mathrm{Z}$ & 149 & 69.0 & 67 & 31.0 & 216 & 14 & 9.4 & 82 & 55.0 & 53 & 35.6 & 149 \\
\hline Erkek & 189 & 75.0 & 63 & 25.0 & 252 & 17 & 9.0 & 126 & 66.7 & 46 & 24.3 & 189 \\
\hline Toplam & 338 & 72.2 & 130 & 27.8 & 468 & 31 & 9.2 & 208 & 61.5 & 99 & 29.3 & 338 \\
\hline
\end{tabular}

$$
\mathrm{X} 2=2.10000 \quad \mathrm{SD}=1 \mathrm{P}>0.05 \quad \mathrm{X} 2=5.43536 \quad \mathrm{SD}=2 \mathrm{P}>0.05
$$

Tablo 1'e göre, k1z öğrencilerin 149'u ( \% 69.0 ), erkek öğrencilerin 189'u (\%75.0 ) beklentilerinin olduğunu belirtmişlerdir.

Beklenti yönünden kız ve erkek öğrenciler arasındaki farklılık istatistiksel olarak önemsiz bulunmuştur $(\mathrm{P}>0.05)$.

Beklentilerin gerçekleşmesi yönünden kız ve erkek öğrenciler arasındaki farklılık araştırıldığında, gruplar arası farklılık istatistiksel olarak önemsiz bulunmuştur $(\mathrm{P}>0.05)$.

Tabloda görüleceği gibi kız öğrencilerin 14’ü ( \% 9.4 ) beklentilerin tamamen, 82'si ( \% 55.0 ) kısmen gerçekleştiğini, 53’ü ( $\% 35.6)$ beklentilerinin hiç gerçekleşmediğini belirtmişlerdir. Erkek öğrencilerin 17'si ( \% 9.0) beklentilerinin tamamen, 126's1 ( \% 66.7 ) kısmen gerçekleştiğini, 46'sı $\quad\left(\begin{array}{l}\% \\ \%\end{array} 24.3\right)$ ise beklentilerinin hiç gerçekleşmediğini belirtmişlerdir. 
TABLO -2 Cinsiyet değişkenine göre beden eğitimi dersinde sağlıklı olabilmek için sportif faaliyetlere katılma konusundaki öğrenci beklentileri

\begin{tabular}{|c|c|c|c|c|c|c|c|c|c|c|c|c|}
\hline \multirow[t]{3}{*}{ Cinsiyet } & \multicolumn{4}{|c|}{ Beklenti } & & \multicolumn{6}{|c|}{ Beklentinin Gerçekleşme Düzeyi } & \multirow[t]{3}{*}{ Toplam } \\
\hline & \multicolumn{2}{|c|}{ Var } & \multicolumn{2}{|c|}{ Yok } & & \multicolumn{2}{|c|}{ Tamamen } & \multicolumn{2}{|c|}{ Kismen } & \multicolumn{2}{|c|}{ Hiç } & \\
\hline & $\mathrm{f}$ & $\%$ & $\mathrm{f}$ & $\%$ & Toplam & $\mathrm{f}$ & $\%$ & $\mathrm{f}$ & $\%$ & $\mathrm{f}$ & $\%$ & \\
\hline $\mathrm{K} 1 \mathrm{Z}$ & 132 & 61.1 & 84 & 38.9 & 216 & 11 & 8.3 & 65 & 49.2 & 56 & 42.4 & 132. \\
\hline Erkek & 177 & 70.2 & 75 & 29.8 & 252 & 28 & 15.8 & 92 & 52.0 & 57 & 32.2 & 177 \\
\hline Toplam & 309 & 66.0 & 159 & 34.0 & 468 & 39 & 12.6 & 157 & 50.8 & 113 & 36.6 & 309 \\
\hline
\end{tabular}

Tablo 5'e göre kız öğrencilerin 132'si ( \% 61.1 ), erkek öğrencilerin 177'si (\%70.2 ) beklentilerinin olduğunu belirtmişlerdir.

Öğrenci beklentileri ile cinsiyet arasındaki gruplar arası farklılık istatistiksel olarak önemli bulunmuştur $(\mathrm{P}<0.05)$.

Beklentilerin gerçekleşmesi yönümden kız ve erkek öğrenciler arasındaki farklılık araştırıldığında, gruplar arası farklılık istatistiksel olarak anlamsız bulunmuştur $(\mathrm{P}>0.05)$.

Tabloda görüleceği gibi kız öğrencilerin $11^{\prime}$ i ( $\% 8.3$ ) beklentilerinin tamamen, $65^{\prime}$ i ( $\%$ 49.2 ) kısmen gerçekleştiğini, 56's1 ( \% 42.4 ) beklentilerinin hiç gerçekleşmediğini belirtmişlerdir. Erkek öğrencilerin 28'i ( \% 15.8 ) beklentilerinin tamamen, 92'si ( \% 52.0 ) kısmen gerçekleştiğini, 57'si ( \% 32.2 ) de beklentilerinin hiç gerçekleşmediğini belirtmişlerdir.

TABLO- 6 Cinsiyet değişkenine göre beden eğitimi dersinde düzgün hareket etme ve iyi duruş alıskanlıkları kazanma konusundaki öğrenci beklentileri

\begin{tabular}{|c|c|c|c|c|c|c|c|c|c|c|c|c|}
\hline \multirow[t]{3}{*}{ Cinsiyet } & \multicolumn{4}{|c|}{ Beklenti } & & \multicolumn{6}{|c|}{ Beklentinin Gerçekleşme Düzeyi } & \multirow[t]{3}{*}{ Toplam } \\
\hline & \multicolumn{2}{|c|}{ Var } & \multicolumn{2}{|c|}{ Yok } & & \multicolumn{2}{|c|}{ Tamamen } & \multicolumn{2}{|c|}{ Kismen } & \multicolumn{2}{|c|}{ Hiç } & \\
\hline & $\mathrm{f}$ & $\%$ & $\mathrm{f}$ & $\%$ & Toplam & $\mathrm{f}$ & $\%$ & $\mathrm{f}$ & $\%$ & $\mathrm{f}$ & $\%$ & \\
\hline $\mathrm{K} 1 \mathrm{z}$ & 154 & 71.3 & 62 & 28.7 & 216 & 51 & 33.1 & 81 & 52.6 & 22 & 14.3 & 154 \\
\hline Erkek & 173 & 68.7 & 79 & 31.3 & 252 & 75 & 43.4 & 79 & 45.7 & 19 & 11.0 & 173 \\
\hline Toplam & 327 & 69.9 & 141 & 30.1 & 468 & 126 & 38.5 & 160 & 48.9 & 41 & 12.5 & 327 \\
\hline
\end{tabular}

$$
\mathrm{X} 2=0.38668 \quad \mathrm{SD} \mathrm{P}>0.05 \quad \mathrm{X} 2=.72454 \quad \mathrm{SD} \mathrm{P}>0.05
$$

Tablo 6'da görüldüğü gibi; kız öğrencilerin 154'ü (\% 71.3 ), erkek öğrencilerin 173’ü (\% 68.7) bu konuda beklentilerinin olduğunu belirtmişlerdir.

Beklenti yönünden cinsiyete göre farklılık araştırıldığında gruplar arası farklılık istatistiksel olarak önemsiz bulunmuştur $(\mathrm{P}>0.05)$. 
Beklentilerin gerçekleşme düzeyi yönünden kız ve erkek öğrenciler arasındaki farklılık araştırıldığında istatistiksel olarak önemsiz bulunmuştur ( $\mathrm{P}>0.05$ ).

Tablo 6'dan da görüleceği gibi kız öğrencilerin 51'i ( \% 33.1 ) beklentilerinin tamamen, 81'i ( \% 52.6 ) kısmen gerçekleştiğini, 22'si ( \% 14.3 ) beklentilerinin hiç gerçekleşmediğini belirtmişlerdir. Erkek öğrencilerin 75'i ( \% 43.4 ) beklentilerinin tamamen, 79'u (\% 45.7 ) kısmen gerçekleştiğini, 19 'u $(\%$ 11.0) da beklentilerinin hiç gerçekleşmediğini belirtmişlerdir.

\section{TARTIŞMA VE SONUÇ}

Araştırmaya göre; fiziksel gelişim sağlama konusunda kız ve erkek öğrenciler arasında anlamlı bir fark bulunamamıştır ( $\mathrm{P}>0.05$ ). Ancak okul değişkenine göre anlamlı bir fark tespit edilmiştir $(\mathrm{P}<0.05)$. Teknik Lise ve Endüstri Meslek Lisesi öğrencileri ve Anadolu Lisesi öğrencilerinin diğer okullara göre daha fazla beden eğitimi dersinden fiziksel gelişim sağlama konusunda beklentilerinin olduğu görülmüştür. Bu bulgu Sunay'ın yapmış olduğu benzer bir çalışma ile paralellik göstermektedir. Beklentilerin gerçekleşme düzeyine bakıldığında ise bu konuda öğrenci beklentilerinin olduğu ancak beklentilerinin gerçekleşmediği görülmüştür.( Sunay ve Ark.1996)

Öğrenci beklentilerinin gerçekleşme düzeyleri cinsiyet ve okul değişkenine göre bir farklılık göstermemektedir. Bu durum farklı cinsiyetteki Öğrencilerin beden eğitimi dersinin fiziksel gelişim sağlama konusunda aynı beklenti içinde olduklarım göstermektedir.

Öğrenciler, sağlıklı olabilmek için sportif faaliyetlere katılma konusunda beklentilerinin olduğunu belirtmişlerdir. Erkek öğrencilerin kız öğrencilere göre daha çok beklentisinin olduğu görülmüştür. Ancak bu beklentilerin gerçekleşmediği tespit edilmiştir. Gökmen ve Schnitger tarafından yapılan benzer bir araştırma ile paralellik göstermektedir. Gökmen ve Schnitger'in araştırmasında üniversite öğrencileri beden eğitimi dersini sağlık ve zindelik kazanmak için seçtiklerini belirtmişlerdir.(Gökmen,H.,Schitger,W., (1981)

Öğrenciler beden eğitimi dersi yoluyla sağlıklarının korunacağı beklentisinin gerçekleşmediğini belirtmişlerdir. Bu sonuç beden eğitimi ders programının içerik olarak sağlık konusunda öğrencileri yeterince bilgilendirmediği ile açıklanabilir

Öğrenciler, beden eğitimi dersinde düzgün hareket etme ve iyi duruş alışkanlıkları kazanma konusunda beklentilerinin olduğunu belirtmişler ancak bu beklentilerin k1z ve erkek ögrencilerde, okullar arasında anlamlı bir fark yaratmadığı tespit edilmiştir ( $\mathrm{P}>0.05$ ). Dolayısıyla farklı cinsiyetteki öğrencilerin yaşları ve gelişim düzeyleri göz önüne alındığında beden eğitimi dersinde düzgün hareket etme ve iyi duruş alışkanlıkları kazanma konusunda benzer duygulan paylaştıkları söylenebilir.

Araştırma bulgularından elde edilen bilgilere göre, lise öğrencilerinin araştırmada belirlenen amaçlara yönelik olarak beklentilerinin olduğu ancak beklentilerinin genellikle kısmen yada hiç gerçekleşmediği sonucuna varılmıştır.

Taşmektepli ve ark. yaptığı araştırma göre; haftalık beden eğitimi ders süresinin, dersle ilgili genel ve özel amaçlara ulaşabilmek için yeterli olmadığı, öğretmenlerin planları hazırlarken müfredatın tamamına değil, daha çok bildikleri konulara öncelik verdikleri, okullarda yeterli 
tesis ve malzeme bulunmadığı ve sportif faaliyetlere okul idarelerinin yeterli desteği vermediği belirlenmiştir.(Taşmektepligil, ve Ark. (2006)

$\mathrm{Bu}$ sonuçlara göre; beden eğitimi dersinin fonksiyonelliğini mevcut durumdan daha ileriye taşımak için okulların müşterek kullanabileceği spor tesislerinin yapılması ve beden eğitimi ders formatın seçmeli spor dersi şekline dönüştürülerek bunlara ihtisas sahibi beden eğitimi öğretmenlerinin görevlendirilmesi uygun olacaktır. (Taşmektepligil,ve Ark. (2006)

Özdağ ve arkadaşlarının yaptığı araştırmada; Muğla ili lise 2 öğrencilerinin fiziksel, sosyal, estetik, spora yönelme ve katılma kapsamında beklentilerinin olduğu belirlenmiş, ancak bu beklentilerinin gerçekleşme düzeyi oldukça düşük olduğu görülmüşsür. Öte yandan, öğrencilerin beden eğitimi dersleriyle estetik güzellik sağlama ve spor dalıyla ilgili yeteneğine ortaya çıkarma kapsamındaki beklentilerinin ve beklentilerinin gerçekleşme düzeylerinde ise anlamlı bir ilişki olduğu belirlenmiştir.( Özdağ, ve Ark.2007)

Öçalan.M., Erdoğdu.M., Ankara ili Yenimahalle ilçesi Orta öğretimde yer alan öğrencilerin beden eğitimi dersi genel amaçlarının gerçekleşme düzeyi konusunda en düşük oranda; "BED, yöresel oyunlarımızı tanıtıp, bunları öğrenmemi kolaylaştırıp keyif almamı sağladı" görüşünü belirtmişlerdir. $\mathrm{Bu}$ bizim yaptığımız çalışma ile paralellik göstermektedir. (Öçalan.M., Erdoğdu.M.,2009)

Yıldıran ve arkadaşları Ankara ilinde yaptıkları araştırmada öğrencilerin beden eğitimi derslerinden önemli beklentilerini ortaya koymuşlar fakat bu beklentilerine rağmen beklentilerinin gerçekleşme düzeyi çok düşük kaldığını tespit etmiişlerdir.(Yıldıran,ve Ark, 1996)

Ova tarafından yapılan bir araştırmada, Belçika ile Türkiye arasındaki beden eğitimi derslerinin ders saati uygulaması, araç-gereç kullanımı ve spor salonu imkanları açısından yapmış olduğu incelemede önemli farklılıklar çıkmıştır. Belçika'da ders saati 3-4 saat iken Türkiye'de 1-2 saat olup,spor salonu olma oranı ise Belçika'da \%90 olup Türkiye'de \%3 seviyelerindedir (Ova,2010)

\section{ÖNERÍLER}

Beden eğitimi dersi öğretim programları öğrenci beklentileri göz önüne alınarak yeniden planlanmalıdır. Hem bedensel hem de ruhsal gelişim içinde olan orta eğitim dönemindeki çocukların fiziksel gelişimine ve motorik özelliklerine göre planlamalar yapılmalıdır. Beden eğitimi dersinde pasif olacak şekilde değil hareket ihtiyacına cevap verecek spor, oyun ve hareket faaliyetlerine yer verilmelidir. Beden eğitimi dersi için tesis, araç-gereç ve malzeme eksikliği giderilmeli öğrenci tarafindan kullanılmasına izin verilmelidir. Okullarda öğrencilerin birbirleriyle kaynaşması ve arkadaşlıklar kurulması için yoğun öğrenci katılımı sağlayacak okul içi sportif yarışmalara yönelik organizasyonlar yapılmalıdır.

Beden eğitimi derslerine genel bilgi derslerinden sonra yer verilmeye çalışılmalıdır. Öğrencilerin beden eğitimi derslerinden daha fazla yararlanmaları için beden eğitimi ders saatleri artırılmalıdır. Beden eğitimi derslerinin daha iyi yürütülebilmesi için ilköğretim okullarına ayrı liselere ayrı beden eğitimi öğretmenleri yetiştirilmelidir. 


\section{REFERENCES}

- DEWEY,J.,(1984) Democracy and Education an Introdustion to Philosophy of Education. Free Press, New York

- *ERTÜRK, S.,(1979) Eğitimde Proğram Geliştirme. Hacettepe Üniversitesi Basımevi, Ankara.

- *VARIŞ, F., (1994) Eğitimde Proğram Geliştirme, Alkım Kitapçılık ve Yayıncılık, Ankara

- *DÖNMEZ, B.,(1995) Beden Eğitimi Öğretmeni Yetiştiren Proğramlardaki Alan Derslerinin Karşılaştırlması. Fırat Üniversitesi Sosyal Bilimler Enstitüsü Yayınlanmamış Doktora Tezi.

- *TAMER, K., (1987) Beden Eğitimi ve Oyun Öğretimi. Anadolu Üniversitesi Yayınları No: 202, Eskişehir

- *ÖZTÜRK, Ü.,(1982) Orta Dereceli Okullarda Beden Eğitimi. Güven Matbaası, İstanbul.

- *UNAT,R.F., (1964) Türkiye'de Eğitim Sisteminin Gelişmesine Tarihi Bir Bakış. Milli Eğitim Basımevi, Ankara.

- *MASSER, L.S., (1990) Teaching For Affective Learning in Elemantary Physical Education, Joperd 61(7) 18-19.

- *GÖKMEN,H., (1983) Orta Öğretim Kurumlarında Beden Eğitimi ve Spor T.E.D Yayınları, Öğretim Dizisi No:6 Şafak Matbaaçılık, Ankara

- *MEB (1988) İlköğretim Okulları, Lise ve Dengi Okullarda Beden Eğitimi Öğretim Proğramları. Milli Eğitim Basımevi.

- *MEB (1973)Milli Eğitim Temel Kanunları. Milli Eğitim bakanlığı Yayını, Maarif Matbaası, İstanbul

- *WILL, G., CARL.E., (1979) Curriculum in Physical Education Prentice Hall, Third Edication.

- *LUMPKIN,A., (1986) Physical Education A Contemporary Intraction, Times Mirror, Mosby Collage Publication

- *SUNAY, Y., SUNAY,H., (1996) Lise Öğrencilerinin Beden Eğitimi Dresinden Beklentileri ve Beklentilerinin Gerçekleşme Düzeyi. Beden Eğitimi ve Spor Bilimleri Dergisi. Cilt: 1,Sayı : 4 Ankara

- *GÖKMEN,H.,SCHITGER,W., (1981) Zorunlu Seçmeli Beden Eğitim Dersleri ve ODTÜ Uygulanabilirliği, Türk- Alman Projesi, Ankara

- *TAŞMEKTEPLİGiL,Y.,ve Ark. (2006) İlköğretim Okullarında Beden Eğitimi Ders Hedeflerinin Gerçekleşme Düzeyi, Spormetre Beden Eğitimi Ve Spor Bilimleri Dergisi, 2006, Cilt:4Sayfa: 139-147

- *ÖZDAĞ, S., ve Ark. (2007) Farklı Cinsiyetteki Lise 2. Sınıf Öğrencilerinin Beden Eğitimi Dersinden Beklentileri Ve Beklentilerinin Gerçekleştirme Düzeyleri, Mehmet Akif Ersoy Üniversitesi Eğitim Fakültesi Dergisi.

- *ÖÇALAN.M., ERDOĞDU.M.,(2009) Ortaöğretim Kurumlarında Beden Eğitimi Dersinin Amaçlarının Gerçekleşme Düzeyi, Niğde Üniversitesi Beden Eğitimi ve Spor Bilimleri Dergisi Cilt 3, Sayı 3,

- *YILDIRAN, İ., YETIM, A. VE ŞENEL, 0.(1996). Farkl1 cinsiyetteki lise öğrencilerinin beden eğitimi dersinden beklentileri. Gazi Üniversitesi, Beden Eğitimi ve Spor Bilimleri Dergisi, 1(1), 52-57.

- *OVA, A., (2010) Belçika ve Türkiye Eğitim sisteminin İncelenmesi. Sakarya Üniversitesi Beden Eğitimi Spor Öğretmenliği Bölümü Araştırma Projesi. Sakarya 